\title{
Pigmented Kamino bodies: a little-known histological finding. Prevalence in 19 cases of Reed nevus
}

\author{
Ana Caroline Barreto Antunes ${ }^{1}$ \\ Paula Silva Ferreira ${ }^{1}$
}

\author{
Aline Caixeta Guimarães Véspoli ${ }^{1}$ \\ Neusa Yuriko Sakai Valente ${ }^{2,3}$
}

DOI: http:/ /dx.doi.org/10.1590/abd1806-4841.20175996

\begin{abstract}
The present study aimed to determine the prevalence of Kamino bodies in Reed nevus, since most studies to date show conflicting data on this issue. This was a retrospective observational study, in which the histopathology of 19 Reed nevus lesions were reviewed. The slides were stained by hematoxylin and eosin and periodic acid-Schiff, with a special focus placed on the identification of Kamino bodies. Some clinical data were also collected. The median patient age was 12 years (range of 2 to 58). The women to men ratio was 5:4. Lesions were located on different parts of the body. Kamino bodies were found in eleven lesions (57.89\%). five showed pigmented Kamino bodies (26.31\%), four non-pigmented Kamino bodies (21,05\%), and $2(10.52 \%)$ had both. Kamino bodies, pigmented or not, are a common histological finding in Reed nevus and may well represent a good marker to differentiate these from malignant melanomas.
\end{abstract}

Keywords: Histology; Nevus, spindle cell; Nevus, pigmented

\section{INTRODUCTION}

The Reed nevus, or pigmented spindle-cell nevus, was first described in 1975, and is a benign melanocytic lesion. Some authors consider it to be a pigmented variation of the Spitz nevus, owing to its histopathological similarity. ${ }^{1-3}$

Its diagnosis is more common in the third decade of life, and women are more commonly affected. In most cases, this lesion is located in the extremities of the limbs. Clinically speaking, it appears as an intensely pigmented, well-circumscribed, and homogeneous lesion of dark brown or black color, which can present quick growth. ${ }^{4,5}$ Upon performing a dermoscopy of the Reed nevus, three different patterns can be found: stellar explosion, globular explosion, or an atypical pattern. ${ }^{6-8}$

Histologically, the Reed nevus presents pigmented spindle cell proliferation, arranged in perpendicular and elongated nests, generally limited to the epidermis. Pagetoid dissemination may be present, usually confined to the lower epidermis. One can also find Kamino bodies (KB), which are pinkish, round globules with irregular edges and stained with PAS, also known as eosinophilic globules, generally located above the papillary dermis. These are comprised of basal membrane, especially laminin and collagens IV and VII., ${ }^{90}$ KBs were originally described in Spitz nevi; however, there are reports of its presence in other lesions, such as Reed nevus, "spitzoid" tumor, and malignant melanoma (MM). ${ }^{11-13}$
Studies show a variable prevalence of KBs in Reed nevus. Witsuba et al., studying 10 cases of Reed nevus, found an $80 \%$ prevalence of KBs that were non-pigmented. ${ }^{1}$ Later, in studies from Bar et al. (15 Reed nevi) and Berlingeri Ramos et al. (7 Reed nevi), no KB was found. ${ }^{14,15}$ The prevalence of KBs in the Spitz nevus is also variable ( $16 \%$ to $86 \%)$; however, they seem to be more common than in the Reed nevus. ${ }^{11,14-18}$

KBs were first described in MM in 1979, but they tested negative for PAS, which may well indicate that they were not authentic. Later, Arbuckle and Weedon described a prevalence of $12 \%$ of KBs in MM, which tested negative for PAS in half of the cases, while in the Spitz nevus, they were positive in $93 \%$. Nonetheless, the images were not published. Moreover, in one quote from Arbuckle, one image shown as a KB may have actually been a dyskeratotic cell in the dermoepidermal junction. ${ }^{11,18}$ Hence, the presence of KBs in MM is uncertain, but they appear to be rare or absent.

The Reed nevus is not rare, it presents clinical and histological characteristics that can mimic MM, and the presence of KBs can aid in differentiating these two lesions characteristics.

The present study evaluates the presence of KBs in the Reed nevus, with a special focus on the identification of its pigmented variation, given that the wide range of studies to date show inconsistent data regarding the prevalence of this histological finding in

Received on 04.05 .2016

Approved by the Advisory Board and accepted for publication on 17.08.2016

Work conducted at Hospital das Clínicas, Faculdade de Medicina, Universidade de São Paulo (HC-FMUSP), São Paulo, SP, Brazil.

Financial support: none.

Conflict of interest: none.

Department of Dermatology, Hospital das Clínicas, Faculdade de Medicina, Universidade de São Paulo (HC-FMUSP), São Paulo, SP, Brazil. Laboratory of Medical Investigation in Mycologia, Faculdade de Medicina, Universidade de São Paulo (LIM 53, FMUSP), São Paulo, SP, Brazil. Dermopathology Laboratory, Dermatology Division, Hospital das Clínicas, Faculdade de Medicina, Universidade de São Paulo (HC-FMUSP), São Paulo, SP, Brazil.

(C)2017 by Anais Brasileiros de Dermatologia 
Reed nevus. In this light, we pose the question of whether or not this finding receives little recognition from pathologists.

\section{METHODS}

This is a retrospective observational study. We searched, in our data base system, all of the cases with the histological diagnosis of Reed nevus in our hospital between June 2007 and March 2015. We found 19 lesions in 18 patients. All of the lesions had their slides (stained with HE and PAS) histologically reviewed, with a special focus placed on the identification of KBs. The clinical data from each case were also reviewed, including the age at the moment of diagnosis, the location of the lesions, and the first diagnostic hypothesis. In two cases an immunohistochemical study was available, using a monoclonal antibody against collagen IV, melan A, HMB-45, and cytokeratins AE-1 and AE-3.

The data were stored, organized, and tabulated in Excel and were submitted to a descriptive analysis, in which only the frequency distribution was used.

\section{RESULTS}

Of the evaluated patients, 10 were women and eight were men, with a woman to man ratio of 5:4. One patient (\#2) had two lesions at different moments. The median age upon diagnosis was of 12 years ( 2 to 58 years).

The lesions were located in different parts of the body, including the head ( $n=1)$, trunk $(n=5)$, upper limbs $(n=8)$, and lower limbs $(n=5)$. Reed nevus was considered as the first diagnosis for 12 lesions (63.15\%), and MM was considered as a possible diagnosis for eight lesions (42.1\%). For two lesions, we were unable to find the initial diagnostic hypotheses. The clinical findings are summarized in table 1. Some clinical photos and dermatoscopies are shown in Figures 1 and 2.

\begin{tabular}{|c|c|c|c|c|}
\hline Patient & Sex & Age & Location & Initial Diagnosis \\
\hline Patient \#1 & M & 12 & Trunk & Reed nevus \\
\hline \multirow[t]{2}{*}{ Patient \#2 } & F & 15 & Trunk & Reed nevus \\
\hline & $\mathrm{F}$ & 18 & Trunk & Reed nevus \\
\hline Patient \#3 & M & 27 & Upper limb & - \\
\hline Patient \#4 & F & 17 & Upper limb & Reed nevus vs melanoma \\
\hline Patient \#5 & M & 19 & Upper limb & Spitz nevus vs Reed nevus \\
\hline Patient \#6 & F & 6 & Upper limb & Reed nevus \\
\hline Patient \#7 & F & 5 & Lower limb & Melanoma vs nevus \\
\hline Patient \#8 & $\mathrm{F}$ & 10 & Face & Reed nevus vs Melanocytic nevus \\
\hline Patient \#9 & M & 2 & Upper limb & Reed nevus \\
\hline Patient \#10 & F & 29 & Trunk & Melanocytic nevus vs melanoma \\
\hline Patient \#11 & M & 43 & Upper limb & Blue nevus \\
\hline Patient \#12 & F & 36 & Lower limb & Melanoma \\
\hline Patient \#13 & M & 6 & Upper limb & Reed nevus vs melanoma vs atypical nevus \\
\hline Patient \#14 & M & 9 & Trunk & - \\
\hline Patient \#15 & M & 8 & Lower limb & Reed nevus \\
\hline Patient \#16 & $\mathrm{F}$ & 58 & Upper limb & Reed nevus vs melanoma \\
\hline Patient \#17 & $\mathrm{F}$ & 5 & Lower limb & Reed nevus vs melanoma \\
\hline Patient \#18 & F & 8 & Lower limb & Melanocytic nevus vs melanoma \\
\hline
\end{tabular}
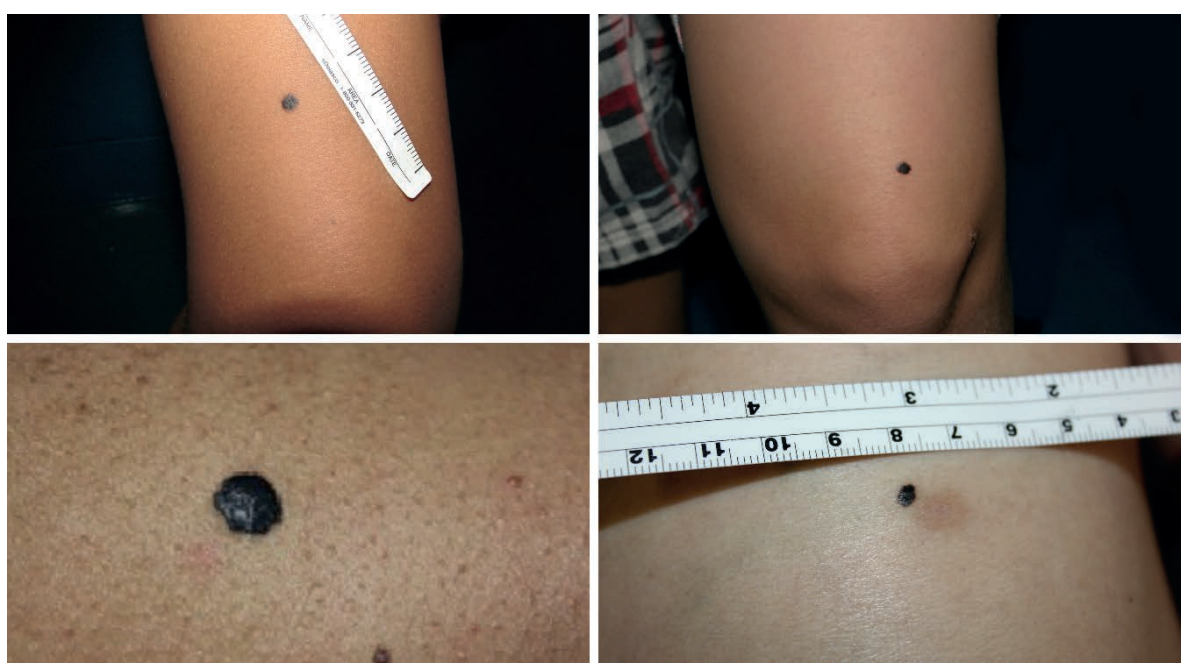

Figure 1:

Reed's Nevus, clinical photos 


\begin{tabular}{lll} 
& \multicolumn{2}{c}{ TABLE 2: Kamino bodies } \\
Patient & Non-pigmented KB & Pigmented KB \\
\hline Patient \#1 & absent & present \\
Patient \#2 & absent & present \\
& absent & absent \\
Patient \#3 & absent & absent \\
Patient \#4 & absent & absent \\
Patient \#5 & present & present \\
Patient \#6 & absent & absent \\
Patient \#7 & absent & absent \\
Patient \#8 & present & absent \\
Patient \#9 & absent & present \\
Patient \#10 & present & absent \\
Patient \#11 & present & present \\
Patient \#12 & present & absent \\
Patient \#13 & absent & present \\
Patient \#14 & absent & absent \\
Patient \#15 & absent & present \\
Patient \#16 & absent & absent \\
Patient \#17 & absent & absent \\
Patient \#18 & present & absent
\end{tabular}
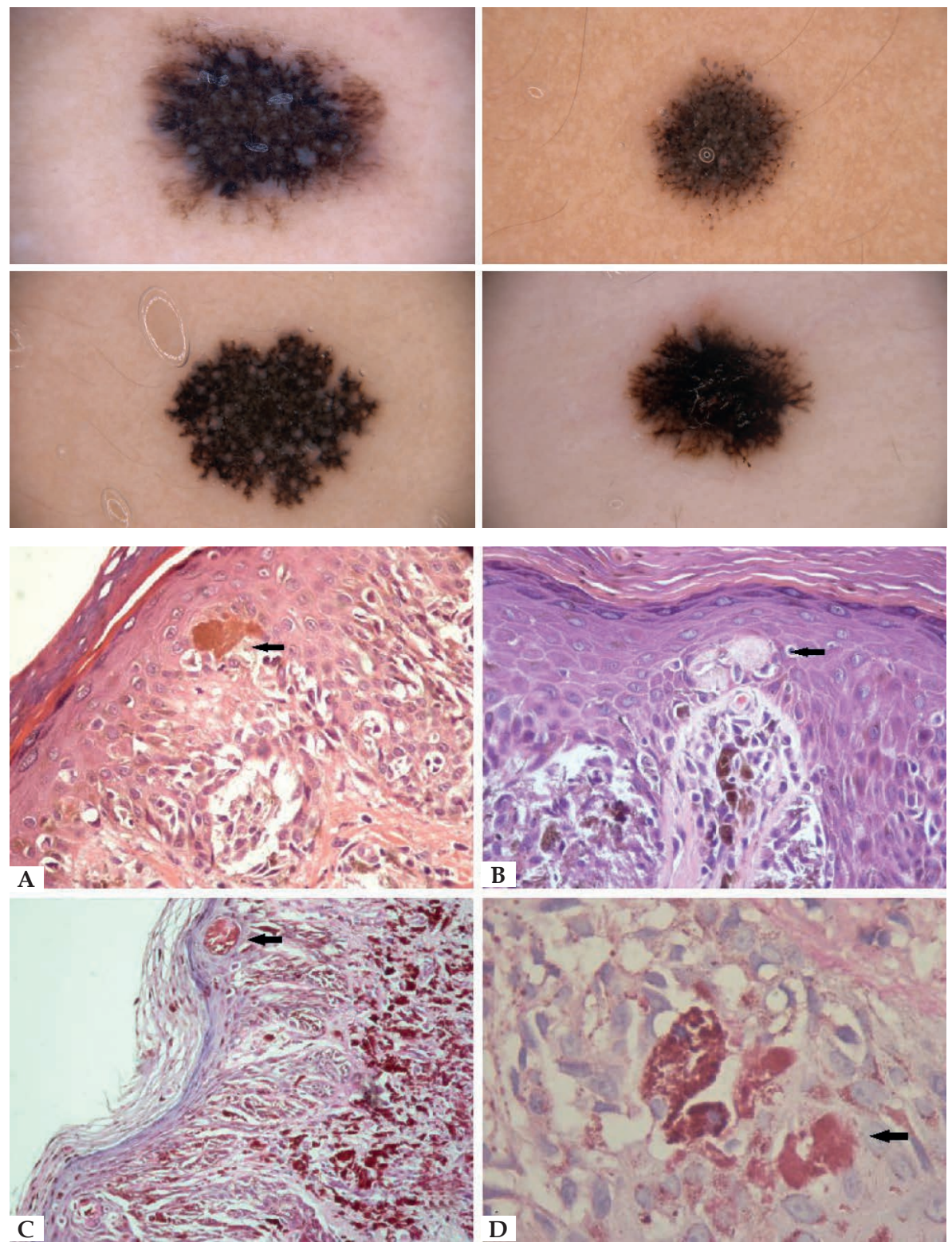

Figure 2:

Reed nevus - dermatoscopic photos

Figure 3:

A: pigmented KB (Hematoxylin \& eosin, 400x);

B: lightly pigmented KB (Hematoxylin \& eosin, 400x);

C: pigmented KB (PAS, 200x);

D: pigmented KB (PAS, 1.000x) 
diagnostic hypothesis in eight cases (42.1\%), showing that it is an important differential diagnosis of this lesion.

In the histological review, KBs were found in 11 lesions. In the literature, the prevalence of these structures in the Reed nevus varies from zero to $80 \%$. The presence of pigmented KB was referred by Weedon; however, studies showing its prevalence were never conducted. ${ }^{19}$ Pigmented KBs were found in five lesions. These structures can be difficult to find if the pathologists does not actively search for them.

In this light, we conclude that KBs, pigmented or non-pigmented, are a common histological finding in both the Reed nevus and the Spitz nevus, and can be a good marker to aid in their differentiation from MM. $\square$

\section{REFERENCES}

1. Wistuba I, Gonzalez S. Eosinophilic globules in pigmented spindle cell nevus. Am J Dermatopathol. 1990;12:268-71.

2. Echevarria R, Ackerman LV. Spindle and epithelioid cell nevi in the adult. Clinicopathologic report of 26 cases. Cancer. 1967;20:175-89.

3. Maize JC, Ackerman AB. Pigmented lesions of the skin. Philadelphia: Lea \&Febiger; 1987.

4. Requena L, Sanchez YE. Pigmented spindle cell nevus. $\mathrm{Br} J$ Dermatol. 1990;123:757-763.

5. Requena C, Requena L, Sánchez-Yus E, Kutzner H, Llombart B, Sanmartín O, et al. Hypopigmented Reed nevus. J Cutan Pathol. 2008;35:87-9.

6. Soyer HP, Kenet RO, Wolf IH, Kenet BJ, Cerroni L. Clinicopathological correlation of pigmented skin lesions using dermoscopy. Eur J Dermatol. 2000;10:22-8.

7. Campos-do-Carmo G, Ramos-e-Silva M. Dermoscopy: basic concepts. Int J Dermatol. 2008;47:712-9.

8. Yoradjian A, Enokihara MM, Paschoal FM. Spitz nevus and Reed nevus. An Bras Dermatol. 2012;87:349-57.

9. Schmoeckel C, Stolz W, Burgeson R, Krieg T. Identification of basement membrane components on eosinophilic globules in a case of Spitz's nevus. Am J Dermatopathol. 1990;12:272-4.

10. LeBoit PE. Kamino bodies: what they may mean. Am J Dermatopathol 2001;23:374-7.

11. Kamino H, Misheloff E, Ackerman AB, Flotte TJ, Greco MA. Eosinophilic globules in Spitz's nevi: New findings and a diagnostic sign. Am J Dermatopathol. 1979;1:323-4.

12. Tom WL, Hsu JW, Eichenfield LF, Friedlander SF. Pediatric "STUMP" lesions: evaluation and management of difficult atypical Spitzoid lesions in children. J Am Acad Dermatol. 2011;64:559-72.

13. Kamino H. Spitzoid melanoma. Clin Dermatol. 2009;27:545-55.

14. Bär M, Tschandl P, Kittler H. Differentiation of pigmented Spitz nevi and Reed nevi by integration of dermatopathologic and dermatoscopic findings. Dermatol Pract Concept. 2012;2:13-24.

15. Berlingeri-Ramos AC, Morales-Burgos A, Sánchez JL, Nogales EM. Spitz nevus in a Hispanic population: a clinicopathological study of 130 cases. Am J Dermatopathol. 2010;32:267-75.
16. Requena C, Requena L, Kutzner H, Sánchez Yus E. Spitz nevus: a clinicopathological study of 349 cases. Am J Dermatopathol. 2009;31:107-16.

17. Walsh N, Crotty K, Palmer A, McCarthy S. Spitz nevus versus spitzoid malignant melanoma: an evaluation of the current distinguishing histopathologic criteria. Hum Pathol. 1998;29:1105-12.

18. Arbuckle S, Weedon D. Eosinophilic globules in the Spitz nevus. J Am Acad Dermatol. 1982;7:324-7.

19. Weedon D. Lentigines, Nevi and Melanoma. In: Weedon D, Strutton G, Rubin AL. Weedon's Skin Pathology. 3rd ed. Edinburgh, United Kingdom: Churchill Livigstone Elsevier; 2010. p. 725.

How to cite this article: Antunes ACB, Véspoli ACG, Ferreira PS, Valente NYS. Pigmented Kamino bodies: a little-known histological finding. Prevalence in 19 cases of Reed nevus. . An Bras Dermatol. 2017;92(3):379-82. 